\title{
La filosofía y el filósofo como ingeniero de la realidad ${ }^{2}$
}

\author{
The Pbilosophy and the Philosopher as \\ an Engineer of the Reality
}

\section{Resumen}

Un debate frecuente a la hora de hablar de filosofía latinoamericana radica principalmente en su existencia verídica y reconocida muchas veces por los ojos del eurocentrismo que impregna al pensamiento filosófico. Sin embargo, el problema debe trascender mucho más allá de la acuñación de un término, debe recaer en el quehacer mismo de aquel que hace filosofía en Latinoamérica; pues al centrar nuestra atención en aquella terminología, caemos fácilmente en ser aquello que llamaremos intérprete de intérpretes. En efecto, saber si somos o no filósofos es un problema mínimo, cuando el horizonte de lo que es o lo que hace un filósofo se ha perdido. De esta forma, el presente escrito se propone reflexionar acerca este problema, evidenciando así las posibles dicotomías a las que se enfrenta el filósofo contemporáneo, pero recreando las diferentes responsabilidades a las que deberá hacer frente.

Palabras clave: filosofía, filósofo, interpretación, intérprete, ingeniero de la realidad.

\begin{abstract}
A recurrent debate when we talk about the LatinAmerican philosophy is its real and recognized to the existence by the euro centrism eyes that permeates the philosophical thought. Although the problem has to go further the coined of a term to the activity of who does the philosophy in Latin-American; because when we can easily fall down in that we call the interpreter of the interpreters. So that, to know that if we are or we are not philosophers is a little problem when the borizon about what a philosopher is or what he/she does is lost. In this way, this article pretends to reflect about this problem, showing evidences of the possible dichotomies faced by the contemporary philosopher and also to recreate the different responsibilities that he/ she has to assume.
\end{abstract}

Keywords: philosophy, philosopher, engineer of the reality.

\section{Recibido el 15 de octubre de 2013 y aprobado el 18 de octubre de 2013}

1 Estudiante de la Maestría en Filosofía Contemporánea de la Universidad San Buenaventura. Filósofo y Licenciado en Filosofía de la Corporación Universitaria Minuto de Dios. Coordinador de Investigación Formativa de la Dirección de InvestigacionesSede Principal, Uniminuto. Correo electrónico: kalesofia@gmail.com

2 Artículo de reflexión. 


\section{El escritor "comprometido" sabe que la palabra es acción;} sabe que revelar es cambiar $y$ que no es posible revelar sin proponerse el cambio

J.P. Sartre (1950)

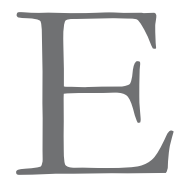

ntre los diferentes pensamientos que se han dado en Latinoamérica podemos encontrar dos grandes grupos: por un lado, los positivistas, volcados completamente sobre la posibilidad de generar pensamiento a partir de los diferentes aportes brindados por la ciencia. Hablamos así de filósofos y pensadores quienes de la mano de la ciencia, el empirismo, el racionalismo, entre otros, dieron la posibilidad de creación y explotación filosófica propia de los latinoamericanos.

Asimismo, en oposición, pero no en negación a éste, se encuentra el segundo grupo denominado los antipositivistas, quienes en reacción a algunas de las posturas positivistas, plantean diferentes modos de pensamiento, ya sean vitalistas, humanistas, marxistas y/o existencialistas. Posiciones que permitieron reproducir diferentes modos de pensar y forjar así gran parte de lo que son las ideologías y posturas políticas de los últimos años. Sin embargo y como ya dije, esta postura no niega al positivismo, sino que por el contrario retoma y reconoce muchos de sus pensamientos, como parte y pieza importante de lo que ha constituido el pensamiento filosófico actual.

No obstante, aún cuando los dos grupos se han encontrado en oposición, han tenido un mismo fin: generar y crear pensamiento latinoamericano. Durante la historia del pensamiento en América Latina se ha debatido y cuestionado frecuentemente si los diferentes aportes de los pensadores latinos pueden o no ser considerados como parte de una filosofía o si por el contrario sólo es una copia del eco filosófico que se da en Europa y que como dijo Heidegger, es imposible que existan filósofos fuera de Alemania o para no ser tan radicales fuera de Europa. Así pues, limitando los demás pensamientos (Asia, África y América) a ser una teología o literatura si mucho, pero eso sí, nunca una filosofía.

Ahora bien, si me preguntan la respuesta acerca de si hay o no filosofía latinoamericana, la respuesta es afirmativa, pues si bien no tenemos un Kant o Hegel entre nuestros pensadores, sí podemos alardear de un José Martí, un Vasconcelos, un Barona y hasta un Francisco Romero. Pensadores que poco o nada tienen que envidiar a los grandes genios del eurocentrismo, pues de igual forma que nosotros no tenemos grandes pensadores como lo son los alemanes, los franceses y los ingleses, ellos no poseen grandes pensadores y filósofos como lo son los nuestros. Empero, el problema va más allá de la tierra en que nacieron o de la lengua que hablaron, pues si de algo podían alardear los pensadores latinos es que a su vez sabían dos o tres idiomas en los que escribían como si fuesen nativos de esas tierras. Sin embargo, tampoco es cuestión de ego académico, pues en muchos de estos personajes corre mucha de la educación europea y hasta impartida por los grandes filósofos de los que aquellos alardean, con los que compartieron, vivieron y generaron amistades muy cercanas.

Así pues, el dilema es mucho más grande, pues a diferencia de lo que se pueda pensar, la filosofía es mucho más que el pensamiento de un individuo; es el pensamiento de un pueblo que tiene voz y quiere hablar a través de sus individuos, en este caso el filósofo, ${ }^{3}$ quién por labor y deber tiene que ser el pensador e intérprete de su

3 Hablo del filósofo, puesto que es el quien me interesa en este escrito. Sin embargo, de lado queda todo el resto de pensadores que denuncian y piensan a diario su sociedad, llámense literatos, sociólogos, científicos, músicos y artistas entre otros. 
época. No obstante, antes de decir algo más sobre este actor debo plantearme los interrogantes a responder en el presente escrito y bajo los que se girará la discusión.

Cuestiono entonces lo siguiente: ¿qué está haciendo el filósofo actualmente en Colombia? Y de ser así, ¿cuál debe ser el papel del filósofo en la actualidad? Y para concluir, ¿`es o no el filósofo el encargado por deber de interpretar y analizar los problemas de su época?

Para responder a estos tres interrogantes se sugiere el siguiente orden metodológico a trabajar, por lo que es preciso aclarar que la finalidad de este escrito es evidenciar un problema que afecta puntualmente a quien les habla, y que si bien es un problema en principio individual o subjetivo, no deja de ser parte de un problema objetivo que afecta el contexto en el que se da. Teniendo claridad en lo anterior, los puntos a tratar son los siguientes:

1. La filosofía para filósofos.

2. Filosofía para todos.

3. El filósofo como ingeniero e intérprete de realidades.

\section{La filosofía para filósofos}

Durante el transcurso de la filosofía desarrollada en Colombia y en Latinoamérica, en general, los diferentes pensadores latinoamericanos se han esforzado arduamente por dar a luz diferentes pensamientos, ideologías y posturas filosóficas propias de su tierra. Durante el transcurso de los últimos siglos, la filosofía en Latinoamérica ha vivido las transformaciones dadas en el pensamiento europeo, a raíz de la gran influencia que estos pensadores generaron en los nuestros.
No obstante, a diferencia de lo que los rumores malintencionados pretenden al afirmar que estos filósofos son sólo reproductores de ideas europeas, nuestros filósofos, al menos en su mayoría, toman no sólo distancia de sus maestros en muchas de sus posturas, sino que adicionalmente les contradicen y hasta realizan posturas sólidas e innovadoras. En efecto, los pensadores latinoamericanos no sólo reconocen el valor de lo europeo, sino que adicionalmente viven y reconocen el valor de lo americano, siendo de esta forma pensadores de su época, de su contexto y sobre todo de su tierra. Lo anterior en oposición a aquellos "filósofos" que creen que la filosofía está lejos de su tierra, o que sólo es digna de hablarse en un idioma específico e incluso se atreven a decir que la filosofía es exclusivamente para "filósofos".

Estos grandes "filósofos" se ufanan de ser grandes sabedores y conocedores de las grandes corrientes filosóficas y sus diferentes representantes. Entonces, con frecuencia nos topamos por el mundo con especialistas en racionalismo, hermenéutica, fenomenología, analítica, existencialismo e idealismo, entre otras. Sin embargo, no es suficiente o si esto parece poco específico, engrandecen e idolatran a un sólo filósofo, hasta el punto de llegar a saber más de él que el mismo filósofo, así es como nos vemos enfrentados a kantianos, marxistas, hegelianos, aristotélicos, espinosistas, nietzscheanos y heideggerianos, entre otros mil más que podría nombrar.

Ahora bien, estos "filósofos" en su ser y en su actuar reproducen y transpiran por sus venas el eurocentrismo filosófico que rechazan y menosprecian cualquier tipo de pensamiento filosófico que se dé en América Latina, resguardados en un purismo y una exclusividad tanto de tierra como de idioma, de los que nunca podrán pertenecer, por razones históricas y geográficas que los atan a este lugar que los vio nacer. Empero, su filoso-

4 Digo filósofos entre comillas porque considero que la filosofía dista mucho de ser lo que ellos consideran ser un filósofo; así que, los diferencio de los filósofos que realmente considero como filósofos de su tierra. 
fía es fruto de la desesperanza y la desconfianza en el pensamiento latino, pero además en su propio pensamiento; pues bajo estos ideales eurocentristas reproducen y transmiten ideas como aquella que un día me hizo saber un profesor: “¿acaso quién es usted para cuestionar a Platón? Preocúpese por entenderlo en vez de estar cuestionándolo" Estas palabras me recordaron a mí y a cualquiera que las escuche a diario de estos "filósofos" que no somos sino unos intérpretes de autores.

Cuando digo intérpretes no me estoy refiriendo a ser hermeneutas, que doy por sentado es una labor seria y rigurosa que sobrepasa incomparablemente mi torpe ejercicio de interpretación de un autor; por el contrario, son aquellas interpretaciones determinadas a las que los docentes en la universidad obligan a sus estudiantes a ver no como un esclarecer el pensamiento del autor, como un deber ser así y no de otra forma, cual si fuera un método a seguir.

En efecto, no son sólo los "filósofos" eruditos los que han nublado nuestro pensamiento, sino que son las academias en general las que desde hace años han venido siendo cuna de este tipo de letrados pensadores, que a diario discuten y pelean por definir quién es más especialista en un autor que otro y quién ha leído más veces los libros de tal filósofo, certificando así que es más docto que cualquier otro.

En consonancia, nos disputamos por ser cada vez más especialistas en asuntos particulares y de un autor específico, pues al parecer, entre más pueda decir uno del autor más "filósofo" es, pues reconocimiento tendrá por doquier. Lo anterior implica que debemos hacer una serie de requerimientos para ser el mejor "filósofo":

En primer lugar, debe educarse en una academia tradicionalista, en donde el pensamiento sea poco motivado y por el contrario se vele por el ejercicio de interpretación de autores. (Así por ejemplo, puede empezar en el pregrado por leer a Kant e intentar demostrar que lo lee bien); a continuación es preciso hacer una maestría en una época y enfocarse en un autor de una escue- la específica que le permita irse formando en la tradición filosófica, (debe releer muy bien a Kant en otras de sus obras).

$Y$ finalmente terminar con un doctorado en un problema del autor, ojo, no suyo, sino del autor, puede ser lo que el éste no vio de sí mismo o lo que le faltó, o cualquier otro, siempre y cuando se encuentre ligado a la fuente reconocida, lo que lo acreditará como un "filósofo" especialista, que personalmente lo que hacen es acreditarlo como un intérprete profesional de un autor específico, (tras la lectura total de toda la obra de Kant puede hacer una interpretación perfecta que lo acredite como un erudito, que le conceda enseñar y juzgar las interpretaciones de cualquier lector de juventud). Pero, ¿es esto realmente un filósofo? ¿Es esto filosofía o sólo es una forma de interpretar y reinterpretar un problema de otros? Y de ser así, ¿dónde queda el pensamiento propio, desapareció o se fusionó con el del autor?

En síntesis, podemos decir que en la actualidad nos estamos enfrentando a un problema de gran magnitud, pues a decir verdad, el hecho de convertirnos en buenos lectores de filosofía hace que toda nuestra labor como filósofos quede relegada a un ser intérpretes de autores, llegando por mucho a ser especialistas y doctos en uno o si se quiere en varios autores. Lo anterior permite que lectores más jóvenes ya no necesiten ir a las cosas mismas, como diría Husserl, sino que por el contrario aprendan de las experiencias y las interpretaciones de intérpretes más reconocidos, lo que fácilmente los ubica como unos buenos intérpretes de intérpretes; conllevando a que esta labor de ser filósofos pierda su enfoque y dirección como se mostrará más adelante.

En este orden de ideas, se puede decir que actualmente el filósofo se ha enajenado de su ejercicio filosófico, puesto que, en primer lugar, ya no se dirige a las cosas mismas, a su contexto, ya no experimenta, ya no analiza su época y hasta en ocasiones ha dejado de ser ese Zoon Politikon, al que reconocía Aristóteles como algo natural en el hombre. En segundo lugar, ha sido formado 
para ser lector de autores, es decir, un intérprete que difícilmente se separa o contradice al autor, además de que la academia misma se lo impedirá. Y en tercer lugar, habiendo cumplido con las anteriores será el encargado de reproducir estos ideales eruditos y academicistas, que promueven la acumulación de saberes, a la vez que relegan la producción y generación de saberes nuevos.

Finalmente, no desconocemos que actualmente las academias de filosofía se caracterizan por ser grandes escuelas productoras de "filosofía" y "filósofos" intérpretes de autores. Realizan investigaciones y estudios exhaustivos sobre filósofos a los que leen con precaución y meticulosidad, tras la esperanza de ver alguna minuciosidad que otro intérprete no haya visto y de la que pueda decir algo que aporte a la gran historia de la filosofía. Como resultado escriben libros brillantes sobre los diferentes temas y filósofos que han trabajado; textos que a su vez son empleados en sus clases para esclarecer a sus estudiantes las diferentes dudas que éstos pueden presentar frente a su temprana e ingenua lectura de las diferentes filosofías, haciendo de esta manera la vida intelectual de sus pupilos un poco más sencilla y menos comprometida. En efecto, esta formación hará de aquellos eunucos filosóficos unos buenos intérpretes de intérpretes, acostumbrados a leer "filosofías" para "filósofos"; que en la mayoría de las ocasiones, poco o nada, afectan estas teorías sus vidas y ni siquiera su realidad. Pues a pesar de muchos, la filosofía se ha convertido en una profesión y hasta en una técnica, ${ }^{5}$ que se aleja por completo de ser un estilo de vida, como sí lo fue para muchos de los filósofos a los que se estudian con rigor y disciplina en estos cursos.

Es preciso preguntar lo siguiente: si todo lo anterior es sólo la decadencia de la filosofía, entonces, ¿cuál debe ser el papel de la filosofía y del filósofo?

\section{Filosofía para todos}

Responder a la pregunta acerca de la labor de la filosofía y del filósofo en la actualidad no va a ser cosa sencilla, por lo que se hace preciso apoyarnos en lo dicho por el filósofo Francisco Romero, como brújula o faro que permitan llevar a buen término la propuesta frente al tema del filósofo como ingeniero e intérprete de realidades.

Para comenzar, partamos del papel que debe cumplir la filosofía antes de hablar del filósofo como fruto de ésta. Así pues, afirmaremos en principio que toda filosofía debe tener como presupuesto y objetivo el ser problemática por naturaleza, pues una filosofía sin problemas se desvanecerá en el aire y el tintero. Así que toda filosofía debe mantenerse en alerta y en constante búsqueda de problemas que la interpelen y le permitan producir saberes nuevos. Pero, ¿qué puede o debe considerarse un problema?

Para hallar un problema o mejor para evidenciar los problemas propios de la filosofía es preciso que giremos la mirada hacia nuestra vida misma, antes que hacia los textos de los que hacemos uso frecuentemente, pues si bien es importante reconocer la teoría y tenerla en cuenta como sustento genealógico e histórico de lo que se ha hecho frente a los diferentes temas tratados en la tradición filosófica, es necesario también superar lo teórico e ir a las cosas mismas, a nuestro mundo circundante; superando así, la interpretación de autores y encaminándonos hacia la interpretación de realidades.

Dice Pablo Guadarrama, haciendo eco de las palabras de Francisco Romero, lo siguiente: "La filosofía desde cierto respecto, es sencillamente la conciencia de la cultura, la cultura humana pensándose a sí misma” (2004, p. 514). En

5 Cuando digo técnica me refiero a aquellas filosofías que se les usa de mala forma, en muchas ocasiones como métodos aplicables para el análisis de diferentes situaciones sociales. Entre estas encontramos la hermenéutica, la fenomenología, filosofía para niños y la lógica entre otras. 
efecto, la filosofía de cada filósofo no es otra que la que pueda producir a partir de su realidad misma, pues ésta no es autosuficiente como dirá Romero a continuación:

[...] la filosofía no es autosuficiente, ella necesita constantemente alimentarse de la realidad que le rodea y de las demás formas del saber y prácticas del hombre. La manera de concebir el avance filosófico - plantea - como determinado por sus propias leyes, según normas y fines derivados de su peculiaridad y naturaleza y corriendo por el encierro de su propio cauce, han sido diversas en los últimos tiempos; pero probablemente yerran todas en lo fundamental, en considerar a la filosofía como un mundo que se basta a sí mismo (2004, p. 515).

En consecuencia, la filosofía deberá sobrepasar los límites que los teóricos, los eruditos y hasta las propias academias de filosofía le ponen; bajo el rótulo absurdo y hasta irrisorio de ser una actividad o ejercicio académico que se nos da aislado de toda realidad, motivo por el que los filósofos han ganado la fama de ser unos desocupados que se la pasan mirando al techo, preguntándose por minuciosidades que a nadie le interesan. En oposición, me atrevo a decir que la filosofía es más que esto, es un ir más allá de la academia, es trascender en el contexto, o si no, ¿qué sentido tendría hacer filosofía? Dice Guadarrama, citando a Romero:

Las condiciones objetivas y exteriores que determinan o fomentan la aparición de las ideas filosóficas y al mismo tiempo les atribuyen ubicación y les aseguran vigencia, parecen ser ante todo las ideas dominantes en el presente y el pasado inmediato, y la concepción del mundo (2004, p. 515).

No obstante, como veremos, Romero no obvia ni incita a olvidar la tradición filosófica, sino que, por el contrario, promueve el aprovechamiento justo y la continuidad y la trascendencia de aquellos saberes previos en su caso próximo el positivismo, al cual, a diferencia de muchos autores y escuelas europeas, no niega, sino que por el contrario les da un papel muy importante dentro de la formación de nuevos pensamientos filosóficos. Empero, toma distancia de aquellos saberes de la tradición, sin dejar de aprovechar beneficioso y productivo que le puedan brindar a su análisis investigativo, como lo especifica el profesor Guadarrama a continuación:

Vencido ahora el positivismo en cuanto filosofía, acallados los ecos de la polémica, con frecuencia agria, que acompañó a su descrédito y ocaso, debe hacerse justicia por lo que representó como poderoso influjo civilizador. La historia de nuestros países no podrá comprenderse sin los impulsos que, en la preparación de la Independencia y en los primeros años de vida autónoma, recibieron de la filosofía de la ilustración, y sin el aporte positivista del siglo XIX. El positivismo significó una aurora renovadora y realista que barrió muchos resabios del pasado colonial y que contribuyó a llevar a Iberoamérica al nivel de la modernidad (2004, p. 517).

Así pues, la solución de la filosofía no está en tomar una aversión frente a lo pasado, sino que por el contrario, es precisamente a partir de esto que al parecer según el ojo del filósofo que lo vea, no se encuentra bien, de donde debemos partir para la producción de un nuevo conocimiento.

Muestra clara de lo dicho anteriormente es la filosofía misma de Francisco Romero, quien a partir de la aprobación de los grandes aportes dados por el positivismo, llega a la crítica de ciertos postulados, como lo son, en primer lugar, la idea de progreso planteada como un desenfreno cientificista y tecnologista, como se ve actualmente con el auge que tiene el capitalismo. En segundo lugar critica la idea positivista que piensa al hombre como algo biológico, evadiendo así al individuo y al hombre como un ser trascendente (esto apuntando hacia un personalismo y el humanismo). Finalmente, plantea la reivindicación de saberes filosófico que habían quedado en el olvido a causa del positivismo de los últimos años. Así es como retoma nuevamente la idea de los valores y el surgimiento de una nueva metafísica, que según él permita aquella trascendencia necesaria para el hombre en la construcción de una realidad, construida 
desde lo inmanente hacia lo trascendente, pues según él "ser es trascender". ${ }^{6}$

Finalmente, la filosofía según Romero, deberá: "ser el camino propio para que el conocimiento se eleve a planos que el saber común jamás podrá realizar" (2004, p. 533). Lo que implica que la filosofía tendrá que adentrarse y ver en los recónditos lugares del pensamiento y de la realidad, permitiendo de esta forma no sólo la posibilidad de analizar el mundo circundante que rodea cada filósofo, sino que además le brinda la opción de modificarlo, cuestionarlo y hasta repensarlo. En efecto, si bien la tarea de todo esto va a recaer sobre el filósofo, es deber de todo hombre pensar su mundo circundante en la medida en que éste lo afecte a cada instante, de lo contrario será labor, casi que un deber ser como diría Kant, del filósofo estar ahí para recordarle a la humanidad, el mundo y la realidad en que vive y del que no se pueden olvidar, como lo veremos a continuación.

\section{El filósofo como ingeniero e intérprete de realidades}

Habiendo hablado y establecido la idea de filosofía que se pretende, es necesario hablar ahora del ingeniero y encargado de llevar a cabo esta idea. Así pues, el llamado a esta labor es el filósofo, no el "filósofo" erudito, pedante y academicista del que ya se habló en el punto uno; sino el filósofo al que se hizo mención al inicio de este escrito, el cual no sólo será capaz de interpretar las ideas de los autores como se ha venido haciendo en los últimos años en las academias de filosofía, sino que además será capaz de actualizarlas en contexto según se requieran, pero, ¿cómo lograr esto?

Del mismo modo que lo vimos anteriormente con la filosofía de Romero, se sugiere lo siguiente a todo aquel lector que por error o fortuna leyese o escuchara este escrito: si la teoría que un filósofo al que lee por x o y motivo no le es útil en el momento, ya sea por falta de práctica o astucia de su parte; para analizar, transformar o enredar su vida, o su contexto; olvídela y déjela en salmuera, al menos hasta que le sea relevante y cobre sentido para su vida misma; de lo contrario estará destinado a caer en una acumulación de saberes y en una erudición, de la que por mucho sacará un ego gigante con el que podrá oprimir a cualquier contrincante que haya acumulado menos saberes que usted. Sin embargo, no confunda este dar sentido a las ideas filosóficas de grandes pensadores, con un utilitarismo en el que pase desapercibido o por alto la riqueza que tiene cada escrito y pensamiento. Por el contrario, es deber suyo, mío y de cualquiera que se dedique a hacer filosofía reivindicar cada saber en pro de un nuevo y vigente pensamiento, que permita hacer una interpretación nueva de la realidad, así como aquellos pensadores lo hicieron de la suya.

En efecto y haciendo eco a lo dicho alguna vez por el profesor Guadarrama, no seamos sólo unas sanguijuelas de teorías y autores. Es preciso atreverse a decir algo, a equivocarse, a ser en últimas constructor de realidades y si dado el caso no se llegase a esto, por lo menos es pertinente preocuparse por interpretarla, de forma que otros puedan hacer uso de esas palabras y trascender en busca de una decodificación de las

6 Para explicar mejor esto dice el profesor Guadarrama en su texto lo siguiente: "A juicio de Romero: "la serie cuerpo físico, ser vivo, psique, espíritu, muestra un crecimiento del trascender, y este crecimiento llega al máximo posible en el espíritu. Lo físico, lo vivo, lo psíquico, lo espiritual, son como etapas en la trascendencia, cada una superior a la que le precede, y en la última el trascender se hace total, absoluto. La escala de los entes es, pues, jerárquica, desde el punto de vista del trascender, y desemboca en un escalón que no puede ser superado. El trascender se realiza a costa de la inmanencia [...] El ingrediente positivo de la realidad es, pues, la trascendencia [...] Lo que la experiencia pone ante los ojos es una trascendencia que despierta poco a poco, que se afianza y extiende, que intenta y descubre caminos nuevos, que se va tornando cada vez más general y segura de sí misma, que al final triunfa sin limitación. Aunque sea provisionalmente, puede adelantarse esta tesis: ser es trascender" (2004, p. 528). 
cosas mismas. No obstante, hay que tener siempre presente que lo importante es ver el entorno propio (mundo circundante) y no el de los filósofos que se leen, pues ellos ya hicieron su trabajo y la pregunta siempre quedará abierta: ¿ahora qué haremos nosotros?

Es claro que el ejercicio es difícil y que la tarea no es sencilla, pero si no es el filósofo el encargado de pensar su época, ¿entonces quién? ¿A qué se dedicará el filósofo, a hacer más filosofía para "filósofos", donde saque a flote su amplia gama de acumulación de saberes, donde muestre las interpretaciones nuevas que hace de un autor, llegando a saber, como diría el profesor Guadarrama, más del mismo filósofo, que el filósofo mismo? Mientras tanto la realidad se deja de lado, en manos de intérpretes como son los políticos, cantantes, futbolistas y empresarios. En suma, aquellos para los que la filosofía es sólo una forma de complementar su discurso dominador; mientras que los pocos y mal pagos docentes se desgastan por no llevar a cabo las exigencias de un sistema y una sociedad malsana, que los obliga a la reproducción en masa de individuos que la alimenten y le permitan dominarlos a su antojo.

Entonces, es preciso que le demos un alto a este asunto y dejemos de rehuir a nuestras responsabilidades sociales. Pues al ser formados en la tradición filosófica se hace imprescindible que empecemos a ser verdaderos filósofos. Porque, de lo contrario, seguiremos viviendo y malgastándonos en conversaciones y discusiones banales y ambiguas, disputándonos quien sabe más de Hegel o quien leyó más obras de Kant o seguiremos mirando si descubrimos cosas nuevas en los autores antiguos y medievales de los que tanto se ha hablado y quizás así podamos ser llamados algún día "filósofos", por una comunidad elitista y erudita que sigue pensando que la filosofía es y será única y exclusiva de los europeos y sus idiomas.

A lo que a mí concierne prefiero nunca ser llamado "filósofo", si para ello tengo que ser un especialista en algún filósofo reconocido, que sí hizo lo que yo no hice por andar interpretando sus obras y sacándoles la última gota de conocimiento, mientras el mundo se muere por ser interpretado. Así que, bien me harían si me libero de los ismos (idealismo, marxismo, platonismo, kantismo...) y los anos (hegeliano, kantiano, derridiano, sartreano...), que tanto mal les hacen a las filosofías mismas de estos autores, a sus lecturas sanas y al mensaje que realmente quisieron trasmitir. Pues a diferencia de lo que algunos hacen de la filosofía actualmente, estos señores sí se tomaron en serio su trabajo como interpretes e ingenieros de sus realidades, no de las de otros filósofos.

\section{Conclusiones}

A modo de conclusión, podemos establecer tres acuerdos fundamentales para llegar a ser estos filósofos e ingenieros de realidades:

Primero, es preciso borrar de nuestras cabezas esa idea del filósofo como intérprete de intérpretes y, por el contrario, enfrentarnos con las cosas mismas por duras que parezcan. Así pues, para conseguir esto es preciso empezar por modificar en una primera instancia la idea de ser filósofos mudos que andan por el mundo tras la búsqueda de una mayoría de edad prometida por Kant y a la que al parecer nunca llegaremos. En segunda instancia, es preciso culminar con la motivación y reproducción de erudición en las academias, como si el ser erudito fuese sinónimo de genio o sabio. $\mathrm{Y}$ en tercera y última instancia, es preciso dejar de lado el yugo que echamos sobre nosotros mismos con aquello del eurocentrismo y sus filosofías para filósofos, pues la filosofía es algo más que una simple ubicación geográfica o un modo de hablar, la filosofía es un estilo de vida que hay que vivir a diario en pro de un fin individual y social.

Por otra parte, es necesario desprender a la realidad de las manos en las que ha caído. Será función del filósofo, y no de otros, develar los problemas de su entorno y despertar de ese le- 
targo a quienes en él se encuentren, ya sea porque nacieron ahí como los habitantes de aquella caverna que hablaba Platón. O simplemente porque a causa del maltrato social no han tenido de otra más que subyugarse a aquella imposición que le otorga su entorno social, como si este fuese el mejor de los mundos posibles del que nos hablaba Leibniz.

Finalmente, debemos convertirnos en aquellos ingenieros de realidades. No obstante, no ha de ser al estilo de los profetas bíblicos, en busca de una tierra prometida; pues los héroes como bien sabemos son una falsa ilusión, que fácilmente borran del mapa. Por el contrario, debemos comprometernos desde nuestros actos mismos, desde nuestros escritos, desde nuestras críticas, desde nuestras clases, pues, como dirían algunos pensadores, lo importante es generar conciencia social, pero para lograr aquello es preciso partir de la conciencia propia. En efecto, por difícil que perezca, es menester nuestro reivindicar a aquellos que nos han servido de ejemplo, es decir, los filósofos a los que tanto vanagloriamos y respetamos, pero no desde un esclavismo de intérpretes, sino desde la lectura del autor como un ejemplo a seguir y no a repetir, cada cual es responsable de su propia época, pues como dice Sartre en el epígrafe, la palabra es acción y esto lo saben todos los escritores comprometidos con su realidad.

Con lo anterior doy por concluido este escrito, no sin antes advertir que esto sólo puede ser producto de mi experiencia vivida como un estudiante de Maestría, que quiere ratificarse a sí mismo el sentido que tiene la filosofía y se rehúsa a creer que ésta se queda en la academia y para los "filósofos" que la leen.

\section{Referencias}

Sartre, J. P. (1950). ¿Qué Es La Literatura? Buenos Aires: Losada.

Guadarrama P. (2004). Positivismo y antipositivismo en América Latina.

La Habana: Ciencias Sociales. 